Ethics

\section{Conflicts of care}

\section{Ward Platt, A Ward Platt}

\section{Could mediation help?}

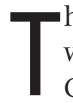
he UK readership of Archives will remember October 2004 for Charlotte Wyatt ${ }^{12}$ and Luke WinstonJones. ${ }^{3}{ }^{4}$ Charlotte was severely disabled following complications of extreme prematurity, and Luke with trisomy 18. In each case the clinical teams believed that active, life prolonging medical interventions would not be in the best interests of the baby. The cases were brought to the civil courts because fundamental and irreconcilable differences between the families and the clinical teams came to an impasse, leaving the respective hospitals with no alternative but to seek a judicial ruling on the management of each child. Observers from other units will either feel that they have been there too, or dread the time that they may find themselves in similar situations.

We should reflect constructively on these cases and be thankful that they remain rare. Most of the time, even in the most difficult situations, we are able to work alongside parents, maintain a bond of trust, and achieve high quality palliative care for infants where the gratuitous prolongation of life is cruel, futile, or impossible. But were the cases of Charlotte and Luke ones where such a resolution was never going to be possible? Or should we wonder whether, with hindsight, either or both of theses situations could have been avoided? It would be of service to the wider community of neonatal care if, after appropriate consideration, the respective teams were able to publish their thoughts; yet the identifiability of the cases would make this impossible without the explicit permission of the families, and it is ethically arguable whether they should even be approached for such permission. We may be doomed not to be able to learn from our recent history, a part of the NHS without an organisational memory.
It would have been particularly valuable to know whether mediation or conciliation was used in either of these cases. If it was, it would appear to have been a failure in so far as the cases came to court anyway; but even if mediation is ultimately unsuccessful in achieving resolution of a problem, it can be of immense value in allowing the parties to define the issues more clearly, and it may uncover issues that have not been apparent on the surface. At an earlier stage than legal proceedings, even apparently polarised attitudes can be susceptible to skilful mediation.

Are there other similar cases around the country in which mediation or conciliation was successful in bringing together professionals and families with seriously divergent views about the management of a baby? Only the participants will know. Yet it would be so valuable for others not to have to reinvent the wheel every time a case like these arises.

Mediation and conciliation can take different forms. It is unlikely that a mediation strategy that attempted to resolve all differences in a single day (a common legal and commercial model) would be successful in a long standing clinical situation. In contrast, an approach that allowed time between meetings with the mediator so that reflection and discussion could take place, and in which the mediator could call on independent specialist clinical advice, might be an attractive option when intransigence appeared to be developing. Such a model is already used in primary care conciliations for the resolution of complaints and could easily be adapted to impasses between clinicians and parents. Mediation/conciliation does not avoid costs, but they would be vastly less than those accrued by a judicial hearing.
Will these rare events become more common? We may find that advances in medical technology collide more often with families whose beliefs are at great variance with those of their medical and nursing carers. The legal frameworks within which paediatricians work in the UK and elsewhere are always likely to lag behind medical innovations and capabilities, creating new hinterlands of uncertainty and greater possibilities for conflict. The internet allows parents access to a great deal of information, but it can be hard to be discerning about the quality of the information, and all too easy to mistake knowledge for wisdom. Our ways of working with parents must evolve to accommodate this challenge, otherwise trusting relationships will be harder to build, and conflicts become more common.

The publicity that always accompanies these cases potentially damages families, carers, and professionals, and the facts are seldom reported without distortion or spin. There is general agreement that courts are not the places where it is optimal to define clinical management, and that every avenue should be explored to obtain resolution of differences without recourse to judicial input. Mediation/conciliation remain underdeveloped approaches outside primary care: perhaps we should give more thought to their use in cases like these.

Arch Dis Child 2005;90:331. doi: $10.1136 /$ adc. 2004.069070

\section{Authors' affiliations}

M Ward Platt, Neonatal Service, Royal

Victoria Infirmary, Newcastle, UK

A Ward Platt, Lay Conciliator, Newcastle Primary Care Trust and North Tyneside Primary Care Trust, UK

Correspondence to: DrM Ward Platt, Neonatal Service (Ward 35), Royal Victoria Infirmary Queen Victoria Road, Newcastle NEl 4LP, ÚK; m.p.ward-platt@ncl.ac.uk

Competing interests: none declared

\section{REFERENCES}

1 Gibb F. Child's best interests guided judge. The Times 8 October, 2004;3DC:5.

2 Dyer C. Baby should be allowed to die, UK court rules. BMJ 2004;329:875.

3 Peek L. Judge says doctors can deny baby ventilation. The Times 23 October, 2004;3C:10

4 Dyer C. Doctors need not ventilate baby to prolong his life. BMJ 2004;329:995 
Chronic pain

\section{Managing chronic pain in children: the challenge of delivering chronic care in a "modernising" healthcare system}

\section{Eccleston}

\section{Commentary on the paper by Lindley et al (see page 335)}

$\mathrm{A}^{\mathrm{n}}$ $\mathrm{n}$ alliance between the healthcare professional, the patient, and the family is at the heart of effective and humane childhood medicine. When patients complain about doctors, and doctors complain about patients, this essential therapeutic alliance has been ruptured or even destroyed. Reason is usurped by fear and concordance gives way to paternalism. It should be remembered that patients often complain about doctors for the same reasons that doctors find some patients difficult to help: when patients don't get better and they are distressed by it. ${ }^{1}$

Drs Lindley, Glaser, and Milla have provided an interesting descriptive account of a selection of the behaviour of a small number of parents with children referred to a single paediatric gastroenterologist at a tertiary referral centre, bringing to our attention issues that should be debated further. ${ }^{2}$ I have brief comments on only two of these issues; other correspondents may wish to raise more. The first relates to the importance of reflexive and quality controlled research, the second relates to the current problems of treating chronic pain in a "modernising" NHS healthcare system.

In this report parents are described in terms of their unwillingness to accept advice, their persistence in seeking further professional opinion and investigation, their use of formal and informal complaints procedures, and their reticence to accept psychological referral. The authors judge some of the complaints to be manipulative. No data are reported on parental mental or physical health, or on any description of family status, or any history of treatments within the NHS. Progress in our understanding of why such unhelpful parental behaviour occurs will be achieved by the specific design of studies with parents as the recruited participants so that the antecedents of complaint and resistance to advice can be fully understood. It will be important, for example, to focus on the realities of the clinical encounter and assess the potential mismatch between the pre-interview expectations of patients, parents, and physicians, and the post-interview memory and understandings of patients and parents. ${ }^{3}$ In addition, how and why chronic pain patients come to feel blamed by the healthcare professionals offering care is of considerable research interest but has yet to be investigated in childhood pain. ${ }^{4}$ There should be no doubt that power dynamics and expectations of care are shifting within the NHS, and the specialist paediatric clinic is perhaps one of the most complex domains within which to understand how "partnership" can be achieved.'

Modernisation of the NHS, as the present UK government fashions it, has some broad stroke policies that are having uncomfortable effects on everyday practice. This article wrestles with a cultural shift, the implications of which, the authors are correct to highlight, have yet to be fully realised. Patient expectations of health and healthcare are being driven up; we are encouraged such as "waiting times" and "global satisfaction". These targets, and the mechanisms for achieving them, such as "complaints procedures", are borrowed from the retail and entertainment business sectors and played out in a centrally governed healthcare system. That there is not a perfect fit should be a surprise to no one, even to those who implemented them. There is nothing, of course, intrinsically wrong with not having to wait and with being satisfied. The problem is that good medicine does not always seek to quickly satisfy. Healthcare professionals working with untreatable pain routinely have to negotiate with patients and families to shift their goals from immediate cure to chronic self-management of persistent or recurrent illness. Accepting that pain cannot be cured, or that illness is to be a fact of childhood and family life is a complex and difficult process that is not easy to achieve. ${ }^{6}$ Until we have fully to believe that what is important in healthcare are organisational indicators understood how to reform everyday hospital procedures to maximise the possibility that patients will be safely given and hear difficult messages, individual doctors will continue to find themselves unheard and complained about.

Many children and adolescents suffer chronic pain that has widespread detrimental effects on themselves and other family members. ${ }^{7-10}$ Parental anxiety and the impact of parenting a distressed and disabled child in pain are often high. This stress is thought to be a major determinant in the style of coping adopted, whether that be the investment of all resources into searching for a cure, or working to change family habits, routines, and parenting styles. Methods for directly targeting parental anxiety and parenting stress are emerging to be potentially crucial in facilitating child improvements. ${ }^{11}$ We should be honest and admit that we know embarrassingly little about how families develop illness promoting or illness defeating coping strategies, and only a little more about how to help. ${ }^{12}$ Until we know more, we should put greater collective effort into building multidisciplinary chronic pain teams in our regional centres. A core task of these teams will be to maintain an alliance between healthcare professionals, patients, and families as they struggle to make sense of the contradictions made prominent when the realities of accepting a life of pain and illness clash violently with our expectations of "modernised" healthcare.

Arch Dis Child 2005;90:332-333.

doi: 10.1136/adc.2003.038778

Correspondence to: Prof. C Eccleston, Director, Pain Management Unit, University of Bath, The Royal National Hospital for Rheumatic Diseases NHS Trust, Bath, UK; c.eccleston@bath.ac.uk

Competing interests: none declared

\section{REFERENCES}

1 Sharpe M, Mayou R, Seagroatt V, et al. Why do doctors find some patients difficult to help? QJM 1994:87: 187-93.

2 Lindley KJ, Glaser D, Milla PJ. Consumerism in healthcare can be detrimental to child health; lessons from children with functional abdominal pain. Arch Dis Child 2005:90:335-7.

3 Kessels RPC. Patient's memory for medical information. J R Soc Med 2003;96:219-22.

4 Eccleston C, Williams A, Stainton Rogers W. Patients' and professionals' understandings of the causes of chronic pain: blame, responsibility and identity protection. Soc Sci Med 1997;45:699-709.

5 Gabe J, Olumide G, Bury M. It takes three to tango: a framework for understanding patient partnership in paediatric clinics. Soc Sci Med 2004;59:1071-9.

6 McCracken LM, Carson JW, Eccleston C, et al. Acceptance and change in the context of chronic pain. Pain 2004; 109:4-7

7 Campo JV, Bridge J, Ehmann M, et al. Recurrent abdominal pain, anxiety, and depression in primary care. Pediatrics 2004;113:817-24. 
8 Perquin CW, Hazebroek-Kampscheur AAJM, Hunfeld JAM, et al. Pain in children and adolescents: a common experience. Pain 2000;87:51-8.

9 Perquin CW, Hazebroek-Kampscheur AAJM Hunfeld JAM, et al. Chronic pain among children and adolescents: physician consultation and medication use. Clin J Pain 2001; 16:229-35.

10 Palermo TM. Impact of recurrent and chronic pain on child and family daily functioning: a critical review of the literature. J Dev Behav Pediatr 2000;21:58-69.
11 Eccleston C, Malleson PM, Clinch J, et al. Chronic pain in adolescents: evaluation of a programme of inter-disciplinary cognitive behaviour therapy of inter-disciplinary cognitive behaviour
(ICBT). Arch Dis Child 2003;88:881-5.

12 Eccleston C, Malleson PM. Management of chronic pain in children and adolescents [editorial]. BMJ 2003;326:1408-9. modulate cytokines, thus reducing the inflammatory response and decreasing intracranial pressure. Early studies of dexamethasone supported a reduction in sensorineural hearing loss with early administration; however, the effect appeared pathogen specific (Haemophilus influenzae type b) and limited to hearing loss. ${ }^{67}$ The current report of McIntyre et al adds one more perspective to the controversy over whether, in fact, dexamethasone administered to children with pneumococcal meningitis improves the outcome. To support this conclusion, McIntyre et al reference a meta-analysis ${ }^{7}$ and a randomised clinical trial (RCT) in children that showed trends favouring the dexamethasone treated group for sensorineural hearing loss (at 3 months). ${ }^{8}$ There are several reasons to question whether these citations resolve the ongoing controversy. In McIntyre et al's meta-analysis of dexamethasone as adjunctive therapy in bacterial meningitis, the authors concluded that the evidence was only suggestive for a benefit in pneumococcal disease. ${ }^{7}$ In addition, one study in particular ${ }^{9}$ had an unusually high mortality $(28 \%)$, and hearing loss was not assessed in younger children. The study included patients from 3 months to 60 years of age and did not specify if the observed effects of dexamethasone occurred in adults or children (or both). Even the authors of the meta-analysis concluded that this study "differed from others" and that statistical evidence of protection from early dexamethasone (for pneumococcal meningitis) is lost if this study is excluded. The RCT cited included children older than 2 years of age and the differences in mortality, neurological outcome, and moderate to severe hearing loss (between 27 patients who received dexamethasone and 26 who received placebo) were "statistically insignificant" at the 6 week follow up. ${ }^{8}$ Statistical significance was achieved only at the 3 month follow up for hearing loss when one child in the dexamethasone treated group was found to have significantly improved hearing compared to the earlier measurement. For several clinical studies that failed to show improved outcomes with dexamethasone, ${ }^{6}{ }^{10}{ }^{11}$ McIntyre et al phy (to rule out increased intracranial pressure) results in increased morbidity. meningitis because of the potential to 
suggest the lack of multivariate analysis as the reason for failing to show the benefit. Unfortunately, their current study will not resolve the conflicting views among those who believe and those who do not that dexamethasone is effective as adjunctive therapy. ${ }^{12}$ What approach should the clinician use?

Concerns about the use of dexamethasone focus on four issues: the need for administration either prior to or concurrent with antibiotic therapy; penetration of antimicrobials in the CSF in the presence of decreased inflammation; potential for dexamethasone to mask signs such as fever that would identify the non-responsive patient; and potential for adverse events. First, there is general agreement that if effective, there is a narrow window for administration of steroids that either proceeds or is concurrent with the initial administration of antimicrobials. Second, the CSF concentrations of vancomycin, ceftriaxone, and rifampin in adults may be reduced when administered with dexamethasone. Although vancomycin appears to penetrate into CSF more reliably in children, and both ceftriaxone and cefotaxime achieve CSF concentrations that result in bactericidal activity against susceptible pneumococci, direct comparisons of CSF concentrations and rapidity of sterilisation in dexamethasone treated and untreated children have not been reported. ${ }^{13-15}$ Furthermore, the potential for diminished CNS penetration of vancomycin in patients receiving adjunctive corticosteroids led to US and UK recommendations, in adults, that rifampin be preferred to vancomycin to achieve optimal antimicrobial activity in the CSF for cephalosporin resistant Streptococcus pneumoniae. ${ }^{16} 17$ Third, clinical signs or symptoms may be decreased in the presence of dexamethasone and the clinician will need to both be vigilant for subtle clinical clues of inadequate response as well as be willing to document that sterilisation of the CSF has occurred when clinical concerns warrant such an approach. Furthermore, two recent studies (using different animal models) showed increased hippocampal neuronal apoptosis and reduced learning capacity and spatial memory when dexamethasone was added to treatment of experimental pneumococcal meningitis. ${ }^{18} 19$ Lastly, some gastrointestinal bleeding has been observed in up to $1-2 \%$ of children with bacterial meningitis administered dexamethasone. The current US recommendations advocate the use of dexamethasone for infants and children with meningitis due to Haemophilus influenzae but only advise consideration for children with pneumococcal meningitis in infants older than 6 weeks of age, reflecting the belief that current studies have not established a clear benefit. ${ }^{20}$

Early diagnosis and administration of antimicrobial therapy that is rapidly bactericidal in the central nervous system is the first principle for optimising the outcome of pneumococcal meningitis. Optimising cerebral blood flow by attention to fluid administration and strategies for reducing intracranial inflammation are attractive adjuncts; however, the optimal strategy for achieving these goals is unclear. Viewing dexamethasone as a first generation approach that reduces markers of CNS inflammation and likely ameliorates some of the morbidity of pneumococcal infection in some children places its use in perspective. Adjunctive approaches employing hypothermia, nitrous oxide inhibitors, or anti-inflammatory molecules such as IL-10 or antitumour necrosis factor-alpha antibody are under evaluation in experimental models. Thus, broad recommendations regarding dexamethasone treatment should be made with caution. Further research of mechanisms of CNS damage and strategies for abating the inflammatory response as well as its direct toxic effects are needed.

Arch Dis Child 2005;90:333-334.

doi: $10.1136 /$ adc. 2004.052928

\section{Authors' affiliations}

S I Pelton, Chief, Section of Pediatric Infectious Diseases, Boston Medical Center, Professor of Pediatrics and Epidemiology, Boston University Schools of Medicine and Public Health, USA

R Yogev, Director, Section of Pediatrics and Maternal HIV Infection, Professor of Pediatrics, Children's Memorial Hospital, Northwestern University Medical School, USA

Correspondence to: Dr S I Pelton, Chief, Section of Pediatric Infectious Diseases, Boston Medical Center, Professor of Pediatrics and Epidemiology, Boston University Schools of Medicine and Public Health, Boston, Massachusetts, USA; spelton@bu.edu

Competing interests: Dr Pelton has acted as an expert witness regarding the outcome of bacterial meningitis during the last five years

\section{REFERENCES}

1 Mclntyre PD, Maclntyre CR, Gilmour R, et al. A population based study of the impact of corticosteroid therapy and delayed diagnosis on the outcome of childhood pneumococcal meningitis. Arch Dis Child 2005;90:391-6.

2 Lebel MH, McCracken GH. Delayed cerebrospinal fluid sterilization and adverse outcome of bacterial meningitis in infants and children. Pediatrics 1989;83:161-7.

3 Kanegaye JT, Soliemanzadeh P, Bradley JS Lumbar puncture in pediatric bacterial meningitis: defining the time interval for recovery of cerebrospinal fluid pathogens after parenteral antibiotic pretreatment. Pediatrics 2001:108:1169-74.

4 van der Flier M, Geelen SP, Kimpen JL, et al. Reprogramming the host response in bacterial meningitis: how best to improve outcome? Clin Microbiol Rev 2003;16:415-29.

5 Mustafa MM, Ramilo O, Sawz-Llorens X, et al. Cerebrospinal fluid prostaglandins, interleukin 1 beta, and tumor necrosis factor in bacterial meningitis. Clinical and laboratory correlations in placebo-treated and dexamethasone-treated patients. Am J Dis Child 1990;144:883-7.

6 Wald ER, Kaplan SL, Mason EO, et al. Dexamethasone therapy for children with bacterial meningitis. Meningitis Study Group. Pediatrics 1995:95:21-8.

7 Mclntyre PB, Berkey CS, King SM, et al. Dexamethasone as adjunctive therapy in bacterial meningitis. A meta-analysis of randomized clinical trials since 1988. JAMA 1997;278:925-31.

8 Kanra GY, Ozen H, Secmeer G, et al. Beneficial effects of dexamethasone in children with pneumococcal meningitis. Pediatr Infect Dis J 1995; 14:490-4.

9 Girgis NI, Farid Z, Mikhail IA, et al. Dexamethasone treatment for bacterial meningitis in children and adults. Pediatr Infect Dis 1999;8:848-51.

10 Arditi M, Mason EO Jr, Bradley JS, et al. Threeyear multicenter surveillance of pneumococcal meningitis in children: clinical characteristics, and outcome related to penicillin susceptibility and dexamethasone use. Pediatrics 1998:102:1087-97.

11 Buckingham SC, McCullers JA, LujanZilbermann J, et al. Pneumococcal meningitis in children: relationship of antibiotic resistance to clinical characteristics and outcomes. Pediatr Infect Dis J 2001;20:837-43.

12 Feigen RD. Use of corticosteroids in bacterial meningitis. Pediatr Infect Dis J 2004:23:355-7.

13 Klugman KP, Friedland IR, Bradley JS Bactericidal activity against cephalosporinresistant Streptococcus pneumoniae in cerebrospinal fluid of children with acute bacterial meningitis. Antimicrob Agents Chemother 1995;39: 1988-92.

14 Friedland IR, Klugman KP. Cerebrospinal fluid bactericidal activity against cephalosporin resistant Stretpococcus pneumoniae in children with meningitis treated with high-dosage cefotaxime. Antimicrob Agents Chemother 1997;41:1888-91

15 Bradley JSS, Farhat C, Stamboulian D, et al. Ceftriaxone therapy of bacterial meningitis: cerebrospinal fluid concentrations and bactericidal activity after intramuscular injection in children treated with dexamethasone. Pediat Infect Dis J 1994;13:724-8.

16 Quagliarello VJ, Scheld WM. Treatment of bacterial meningitis. N Engl J Med 1997;336:708-16

17 Kirsten Møller, Peter Skinhøj. Guidelines for managing acute bacterial meningitis. BMJ 2000;320:1290.

18 Leib SL, Heimgartner C, Bifrafe YD, et al. Dexamethasone aggravates hippocampa apoptosis and learning deficiency in pneumococal meningitis in infants rats. Pediatr Res 2003;54:353-7.

19 Zysk G, Bruck W, Gerber J, et al. Antiinflammatory treatment influences neuronal apoptotic cell death in the denate gyrus in experimental pneumococcal meningitis. J Neuropathol Exp Neurol 1996;55:722-8.

20 American Academy of Pediatrics. Pneumococcal infections. In: Pickering L, ed. 2003 Report of the Committee on Infectious Diseases. 26th edn. Elk Grove Village, IL, 2003:493. 